\title{
Sleep disturbances among Chinese clinical nurses in general hospitals and its influencing factors
}

\author{
Hongyun Dong ${ }^{*} \mathbb{D}$, Qiong Zhang, Zihua Sun, Fengxin Sang and Yingzhi Xu
}

\begin{abstract}
Background: This study aimed to determine the prevalence of sleep disturbances among clinical nurses in general hospitals in Mainland China, and identify its associate factors.

Methods: Using a cross-sectional design, a total of 5012 clinical nurses selected by random cluster sampling completed the survey on the Pittsburgh Sleep Quality Index (PSQI), measures of quality of life indexed by the Medical Outcomes Study 12-item Short-Form Health Survey, occupational stress evaluated by the Job Content Questionnaire, lifestyle and sociodemographic details.

Results: The average PSQI score of 4951 subjects was $7.32 \pm 3.24$, including 3163 subjects with PSQI $\geq 5$, accounting for $63.9 \%$. Multivariate Logistic regression analysis showed that the risk factors for sleep disturbances in nurses were female gender, the Emergency department and ICU, many years of service, high night shift frequency, professional status: primary and intermediate, employment status: temporary, poor quality of life: poor mental health, low perceived health, high occupational stress (high psychological demand, low job control and low workplace social support).

Conclusions: Sleep disturbances are highly prevalent among clinical nurses in general hospitals in Mainland China. Many of the factors listed above were associated with the prevalence of sleep disturbances in nurses, and occupational stress plays an important role in the development of sleep disturbances in Chinese clinical nurses.
\end{abstract}

Keywords: Sleep disturbance, Nurse, Stress, Risk factor, Epidemiology

\section{Background}

As it is known, sleep is a necessary part of our life. Sleep difficulties are ubiquitous and a common complaint among the general population in Western countries, with rates of self-reported insomnia ranging between 10 and $48 \%$ [1-4]. Long-term sleep problems could lead to serious effects such as thought retardation, memory loss, slow response, low spirit, irritability and even the increase in the possibility of depression and suicidal tendency $[5,6]$. Chronic sleep problems have also been associated with greater work absenteeism [7] and workrelated accidents or injuries $[4,8-10]$.

Nurses, as a special occupational group, bear relatively high mental stress and a large amount of job tasks in

\footnotetext{
* Correspondence: ayouwang@163.com

Shouguang People's Hospital, NO. 45, Jiankang Street, Shouguang, Weifang, Shandong Province, China
}

caring for patients [11, 12]. Moreover, clinical nurses need to keep an all-night vigil. This working mode makes their sleep time irregular [13-15]. The sleep quality problem of nurses has become a prominent social focus [16]. Studies have shown that sleep disturbances in nurses not only influences their own health, but also affects nursing quality and even the psychological health and treatment process of patients [17]. However, there has been limited research about current sleep disturbance status among clinical nurses in Mainland China. At present, little is known about the risk factors of their turbances. is believed to be a significant factor in many diseases 18-23]. Clinical nurses have stressful jobs, are frequently on rotating work shifts, undergo emotional stress, and work long hours every day due to their job 
requirements [24-27]. Therefore, a certain correlation between stress and sleep disturbances among clinical nurses was hypothesized.

Our study analyzed the present sleep disturbance status among clinical nurses working in general hospitals in Mainland China, the differences in the sleep disturbances of nurses with different gender, age, marital status, educational background, professional status, employment status, years of service and departments, and factors that influence sleep disturbances in nurses. The relevance between sleep disturbances and occupational stress in nurses was also analyzed, in order to provide a basis for improving the sleep quality of nurses, relieve their occupational stress, and promote their physical and psychological health.

\section{Methods}

\section{Sample}

Considering data collection quality and availability, six general hospitals were selected by random cluster sampling from among all tertiary referral hospitals (38 tertiary referral hospitals in total) in Shandong Province, China. Among the nurses in the above six hospitals, whole clinical nurses who have worked for at least 1 year were selected and interviewed. Exclusion criteria were as follows: nurses (679 in total) whose sleep was affected by other causes such as drinking tea (at least once a day), drinking liquor (at least once a day), disease (heart failure, hyperthyroidism, heartburn, restless leg syndrome, chronic pain, etc.), family history of sleep disorders and taking medicines. Considering the convenience and economic efficiency during the survey, 367 nurses who took a marriage leave, maternity leave, sick leave, and leave for personal affairs were not included. A total of 5012 clinical nurses completed our questionnaire from May 2015 to December 2015. The study was approved by the Ethics Committee of Shouguang People's Hospital. All participants in the study were voluntary and provided a written informed consent before participating into this survey. However, 61 questionnaires that lacked the key variables or were filled in irregularly were eliminated. Therefore, 4951 subjects were included.

\section{Survey questionnaire}

The self-administered questionnaire comprised of four sections, and it took the subjeccts approximately $20 \mathrm{~min}$ to complete.

\section{Sleep disturbances}

The Pittsburgh Sleep Quality Index (PSQI) [28] was employed in the present study to estimate the prevalence of sleep disturbances. The PSQI evaluates multiple dimensions of sleep over a 1-month period [29-31]. Nineteen individual items generate seven component scores: subjective sleep quality, sleep duration, sleep latency, habitual sleep efficiency, sleep disturbances, the use of sleeping medications, and daytime dysfunction [29]. The seven component scores were summed for one global score of subjective sleep quality (range: 0-21), and higher scores represent poorer subjective sleep quality [29]. The Chinese version of the PSQI has good overall reliability $(r=0.82-0.83)$ and test-retest reliability $(r=0.77-0.85)$ [28]. A PSQI global score $>5$ yielded a sensitivity of $98 \%$ and a specificity of $55 \%$, as a marker for poor sleep in primary sleep disturbance sufferers vs. healthy controls [28]. Respondents were classified as having sleep disturbances if they obtained a PSQI global score $>5$ [28-31].

\section{Health-related quality of life (QoL) and measuring scales} The Chinese version of the 12-item Short Form Health Survey (SF-12) was used to measure QoL. SF-12 is a practical scale for large group comparisons with a focus on overall physical and mental health outcomes [32-34]. Researches have indicated that the Chinese version of SF-12 is an effective measurement tool for the Chinese population [35]. It is feasible and credible [36]. The present study used two components from the scale in the current analysis: Mental Component Summary (MCS) score and Physical Component Summary (PCS) score. These scores were based on weighting responses to all 12 items, with higher scores indicating better QoL.

\section{Sociodemographic characteristics and occupational factors}

Sociodemographic and occupational data were gathered on sex, age, education level, marital status, employment status (permanent vs. temporary), departments, number of night shifts per month, years of service, and professional status (registered, primary, intermediate, and senior/deputy senior).

\section{Occupational stress}

Occupational stress was assessed by a validated Chinese version questionnaire [37-39]: Job Content Questionnaire (JCQ). The 22-item JCQ, based on the Job Demand Control Support model [40], consists of three dimensions: psychological demand (five items), job control including skill discretion (six items) and decisionmaking authority (three items), and workplace social support including coworker social support (four items) and supervisor social support (four items) [38, 41]. For each item, the response was recorded using a four-point Likert scale ranging from 1 (strongly disagree) to 4 (strongly agree). The Chinese version of JCQ is a reliable and valid tool for measuring job stressors of the Chinese occupational groups [38]. In the study, Cronbach's $\alpha$ coefficient for the psychological demand subscale was 0.75 , 
while those for the job control and workplace social support subscales were 0.87 and 0.86 , respectively.

\section{Statistical analysis}

Statistical analysis was performed using SPSS version 18.0. Differences between with and without sleep disturbances were examined by single-factor chi-square test (for categorical variables) and independent t-test (for continuous variables). Odds ratios (ORs) and 95\% confidence intervals $(95 \% \mathrm{CI})$ were calculated to examine the association of sleep disturbances with occupational, psychological, QoL and demographic factors using multivariate logistic regression analysis. Initially, univariate analyses were calculated, with each of the potential explanatory variables as independent variables, and sleep disturbances as the dependent variable. Pre-selection for the entry of all associated factors into the multivariate logistic regression model required a $P$-value of $<0.05$ in the univariate analyses. A 5\% significance level was accepted for all tests.

\section{Results}

\section{General conditions}

The average age of the 4951 nurses was $28 \pm 6$ years old, including 284 male subjects (5.74\%) and 4667 female subjects $(94.26 \%)$. The average PSQI score was $7.32 \pm 3.24$, including 3163 subjects with a PSQI $\geq 5$, accounting for $63.9 \%$.

\section{Comparison of different research subjects with and without sleep disturbances}

Table 1 shows that sleep disturbances were statistically related to age, gender, department, years of service, night shift frequency per month, professional status and employment status $(P<0.05)$. Both marital status and educational background were not statistically related to sleep disturbances in nurses.

\section{Quality of life factors associated with sleep disturbances} Results of the univariate analyses revealed that the mean scores of SF12-PCS, SF12-MCS, and perceived health in the past 3 months between subjects with and without sleep disturbances were statistically different $(P<0.05$, Table 2).

\section{Relevance between sleep disturbances and occupational stress}

In terms of the JCQ, the mean scores of decisionmaking authority, skill discretion, psychological demand, supervisor social support and coworker social support between subjects with and without sleep disturbances were statistically different $(P<0.05$, Table 2$)$.
Logistic regression analysis of multiple factors influencing sleep disturbances

Table 3 shows that sleep disturbances revealed an independent relevance with gender, department, years of service, professional status, night shift frequency per month, employment status, QoL (mental health), perceived health in the past 3 months, decision-making authority, skill discretion, psychological demand, supervisor social support and coworker social support. In other words, the risk factors for sleep disturbances in nurses were female gender, ICU and Emergency Department, many years of service, high night shift frequency, professional status: primary and intermediate, employment status: temporary, poor QoL: poor mental health, low perceived health, high occupational stress (high psychological demand, low job control and low workplace social support).

\section{Discussion}

Analysis of sleep quality among clinical nurses in general hospitals in mainland China

To our knowledge, this is the first large-scale survey concerning sleep disturbances and associate risk factors of clinical nurses in Mainland China. Participants were sampled from six randomly selected tertiary-level hospitals of different cities in Shandong Province, which improves the generalizability of the results for clinical nurses working in tertiary hospitals in China. The overall prevalence of sleep disturbances in clinical nurses in general hospitals in Mainland China was $63.9 \%$, which was higher than the general population [1, 2, 7, 42-45]. Using structured questions, an earlier population-based study $(n=9851)$ reported that the overall prevalence of insomnia among Hong Kong Chinese was at $11.9 \%$, with females being at higher risk for insomnia than males [44]. Other researchers in Tehran [46] found that $53.1 \%$ of health care workers had sleep disturbances measured by PSQI, which was lower than that in our finding. A pilot study in Taiwan using the same standard of PSQI [47] also revealed that nurses were most likely to suffer from sleep disturbances with an OR of 5.51 (95\% CI: 2.09-14.51), compared to other hospital staff (physician OR $=1$ ). Therefore, clinical nurses are prone to have sleep disturbances than other health care workers.

In China, clinical nurses in general hospitals receive and treat many patients with critical disease, difficult diseases, and major surgery. As such, for nurses in general hospitals, updating their knowledge hierarchy in time and boosting their clinical practice ability are necessary, which may result in potential pressure on nurses. Therefore, the sleep disturbances of clinical nurses may be the focus of more attention. 
Table 1 Comparison of different research subjects with sleep disturbances

\begin{tabular}{|c|c|c|c|c|c|}
\hline Factor & NO. of subjects & Subjects with PSQI > 5 & Prevalence (\%) & $x^{2}$ & $p$ \\
\hline Gender & 4951 & 3163 & 63.9 & 8.15 & 0.004 \\
\hline Male & 284 & 159 & 56.0 & & \\
\hline Female & 4667 & 3004 & 64.4 & & \\
\hline Age & & & & 183.836 & $<0.001$ \\
\hline $20-29$ & 1932 & 1057 & 54.7 & & \\
\hline $30-39$ & 1455 & 934 & 64.2 & & \\
\hline $40-49$ & 987 & 689 & 69.8 & & \\
\hline 50 and above & 577 & 483 & 83.7 & & \\
\hline Marital status & & & & 1.534 & 0.215 \\
\hline Married & 3187 & 2016 & 63.3 & & \\
\hline Unmarried & 1764 & 1147 & 65.0 & & \\
\hline Years of service & & & & 159.765 & $<0.001$ \\
\hline $1-9$ & 1893 & 1012 & 53.5 & & \\
\hline 10-19 & 1421 & 948 & 66.7 & & \\
\hline $20-29$ & 953 & 705 & 74.0 & & \\
\hline$\geq 30$ & 684 & 498 & 72.8 & & \\
\hline Educational background & & & & 2.629 & 0.453 \\
\hline Lower than junior college & 1269 & 792 & 62.4 & & \\
\hline Junior college & 2063 & 1314 & 63.7 & & \\
\hline Bachelor & 987 & 643 & 65.1 & & \\
\hline Master or above & 632 & 414 & 65.5 & & \\
\hline Night shift frequency (per month) & & & & 29.279 & $<0.001$ \\
\hline Few & 831 & 468 & 56.3 & & \\
\hline General & 1921 & 1224 & 63.7 & & \\
\hline Many & 2199 & 1471 & 66.9 & & \\
\hline Department & & & & 14.751 & 0.022 \\
\hline Internal medicine & 1752 & 1101 & 62.8 & & \\
\hline Surgical department & 1307 & 811 & 62.1 & & \\
\hline of pediatrics & 431 & 278 & 64.5 & & \\
\hline of gynecology and obstetrics & 373 & 237 & 63.5 & & \\
\hline Emergency department & 605 & 412 & 68.1 & & \\
\hline ICU & 264 & 189 & 71.6 & & \\
\hline Operating room & 219 & 135 & 61.6 & & \\
\hline Employment status & & & & 14.028 & $<0.001$ \\
\hline Permanent & 2483 & 1523 & 61.3 & & \\
\hline Temporary & 2468 & 1640 & 66.5 & & \\
\hline Professional status & & & & 10.37 & 0.016 \\
\hline Registered nurse & 1069 & 671 & 62.8 & & \\
\hline Primary & 2127 & 1408 & 66.2 & & \\
\hline Intermediate & 934 & 589 & 63.1 & & \\
\hline Senior/deputy senior & 821 & 495 & 60.3 & & \\
\hline
\end{tabular}


Table 2 Relationship between occupational stress, quality of life and sleep disturbances among clinical nurses

\begin{tabular}{|c|c|c|c|c|c|c|}
\hline \multirow[t]{2}{*}{ Factor } & \multicolumn{2}{|c|}{ Sufferers } & \multicolumn{2}{|c|}{ Non-sufferers } & \multirow[b]{2}{*}{$t$} & \multirow[b]{2}{*}{$P$} \\
\hline & Mean & Standard deviation & Mean & Standard deviation & & \\
\hline \multicolumn{7}{|l|}{ JCQ } \\
\hline Skill discretion & 17.23 & 2.16 & 15.54 & 2.78 & 23.775 & $<0.001$ \\
\hline Decision-making authority & 9.75 & 2.49 & 11.16 & 2.95 & -17.880 & $<0.001$ \\
\hline Psychological job demands & 16.26 & 3.78 & 12.23 & 4.75 & 32.770 & $<0.001$ \\
\hline Supervisor social support & 11.27 & 2.73 & 14.19 & 3.05 & -34.632 & $<0.001$ \\
\hline Coworker social support & 11.91 & 2.29 & 13.24 & 2.97 & -17.583 & $<0.001$ \\
\hline \multicolumn{7}{|l|}{ Quality of life } \\
\hline SF12-PCS & 41.57 & 6.87 & 42.29 & 8.03 & -3.329 & $<0.001$ \\
\hline SF12-MCS & 35.34 & 6.21 & 37.51 & 6.38 & -11.694 & $<0.001$ \\
\hline Perceived health in the past 3 months & 1.62 & 0.64 & 2.11 & 0.66 & -25.585 & $<0.001$ \\
\hline
\end{tabular}

Table 3 Logistic regression analysis of multiple factors influencing sleep disturbances

\begin{tabular}{|c|c|c|c|c|c|c|}
\hline \multirow[t]{2}{*}{ Variables and assignment } & \multirow[t]{2}{*}{ B } & \multirow[t]{2}{*}{ S.E. } & \multirow[t]{2}{*}{$P$} & \multirow[t]{2}{*}{$\mathrm{OR}$} & \multicolumn{2}{|c|}{$95 \%$ C.I. for OR } \\
\hline & & & & & Lower & Upper \\
\hline Gender ( 1 = male, 2 = female) & 0.478 & 0.197 & $<0.001$ & 1.613 & 1.096 & 2.373 \\
\hline Years of service: 1-9 & & & & 1.000 & & \\
\hline $10-19$ & 0.486 & 0.118 & 0.016 & 1.626 & 1.290 & 2.049 \\
\hline $20-29$ & 0.613 & 0.122 & 0.003 & 1.846 & 1.453 & 2.345 \\
\hline$\geq 30$ & 0.499 & 0.108 & 0.007 & 1.647 & 1.333 & 2.035 \\
\hline Night shift frequency per month: Few & & & & 1.000 & & \\
\hline General & 0.425 & 0.131 & 0.017 & 1.530 & 1.183 & 1.977 \\
\hline Many & 0.621 & 0.115 & $<0.001$ & 1.861 & 1.485 & 2.331 \\
\hline Department: Internal medicine & & & & 1.000 & & \\
\hline Surgical department & -0.126 & 0.121 & 0.575 & 0.882 & 0.695 & 1.118 \\
\hline of pediatrics & 0.109 & 0.218 & 0.184 & 1.115 & 0.727 & 1.710 \\
\hline of gynecology and obstetrics & 0.113 & 0.193 & 0.371 & 1.120 & 0.767 & 1.634 \\
\hline Emergency department & 0.429 & 0.118 & 0.021 & 1.536 & 1.219 & 1.935 \\
\hline Operating room & 0.108 & 0.131 & 0.260 & 1.114 & 0.862 & 1.440 \\
\hline ICU & 0.795 & 0.201 & 0.007 & 2.214 & 1.493 & 3.284 \\
\hline Professional status: Registered nurse & & & & 1.000 & & \\
\hline Primary & 0.509 & 0.127 & $<0.001$ & 1.664 & 1.297 & 2.134 \\
\hline Intermediate & 0.428 & 0.114 & 0.011 & 1.534 & 1.227 & 1.918 \\
\hline Senior/deputy senior & -0.227 & 0.112 & 0.013 & 0.797 & 0.640 & 0.993 \\
\hline Employment status ( 1 = permanent, 2 = temporary) & 0.337 & 0.115 & $<0.001$ & 1.401 & 1.118 & 1.755 \\
\hline \multicolumn{7}{|l|}{ JCQ } \\
\hline Skill discretion & 0.347 & 0.117 & 0.008 & 1.415 & 1.125 & 1.779 \\
\hline Decision-making authority & -0.489 & 0.105 & $<0.001$ & 0.613 & 0.499 & 0.753 \\
\hline Psychological job demand & 0.305 & 0.098 & $<0.001$ & 1.357 & 1.120 & 1.644 \\
\hline Supervisor social support & -0.307 & 0.123 & $<0.001$ & 0.736 & 0.578 & 0.936 \\
\hline Coworker social support & -0.268 & 0.114 & $<0.001$ & 0.765 & 0.612 & 0.956 \\
\hline \multicolumn{7}{|l|}{ Quality of life } \\
\hline SF12-MCS & -0.319 & 0.137 & 0.005 & 0.727 & 0.556 & 0.951 \\
\hline Perceived health in the past 3 months & -0.284 & 0.107 & 0.013 & 0.753 & 0.610 & 0.928 \\
\hline
\end{tabular}




\section{Influence of sociodemographic and QoL factors on sleep disturbances in clinical nurses}

In line with existing epidemiological data [44, 48, 49], our findings revealed that female nurses suffered from sleep disturbances more easily than male nurses. This finding may be related to the female physiological and psychological features. In China, female nurses need to work and take care of their family at the same time, such that their life pressure is higher than that of male nurses. Sleep disturbances are frequently symptoms of anxiety and depression, which may be reflected in the sleep quality difference caused by gender difference $[48,50]$. Thus, their sleep quality may be affected more easily. Therefore, more attention should be paid to the sleep quality of female nurses.

Meanwhile, nurses with primary and intermediate professional status may suffer from sleep disturbances more easily. The Ministry of Health in China classifies the grade of nurses according to their years of service, working ability and capacity for scientific research, as follows: registered, primary, intermediate, deputy senior, and senior. Primary and intermediate nurses still need to master the specialty proficiently and put in considerable effort for in-depth learning. Meanwhile, primary and intermediate nurses are faced with increasing pressure of further job title evaluation.

Our results replicated existing data that sleep disturbances were associated with impaired QoL [51, 52]. However, in our study, only the mental health component was retained in the final model of regression analyses for sleep disturbances. Poor mental health was associated with sleep disturbances in clinical nurses, which was consistent with previous reports [1, 53-55]. These findings suggest that the pathway that mediated between sleep disturbances and QoL was more likely to be psychological, rather than physical [56].

\section{Effects of job nature and department on sleep disturbances}

In our study, more years of service was significantly associated with a greater prevalence of sleep disturbances, indicating that the job nature of clinical nurses affects the prevalence of sleep disturbances among nursing staff. Other researchers have also revealed that more years of service is a risk factor of sleep disturbances [57]. As service years increases, nurses would shoulder greater work pressure and face a more complicated personal relationship, which could all lead to the attack of sleep disturbances; while the sleep quality of nurses with more than 30 years of service would slightly be better. This may be due to the fact that nurses with more than 30 years of service are going to retire, undertake less job tasks, and do not have to take night shifts.
This research indicates that PSQI scores have significant differences in different departments. The departments that resulted in sleep disturbances among nurses most easily are ICU and the Emergency Department. Nurses in the ICU had the highest risk of sleep disturbances, which may be related to the heavy workload, long-term contact with critical and seriously ill patients, evident occupational exposure, high work intensity and high pressure. For example, considering the particularity of the ICU, family members are not allowed to accompany and attend to patients. Thus, clinical nurses of the ICU bear all basic nursing work. The research of other study [58] also revealed that clinical nurses in the ICU show poor sleep quality, fatigue, drowsiness, anxiety and depression. However, the root causes of these findings are unconfirmed. Nurses in the Emergency Department rank top 2 in terms of the occurrence rate of sleep disturbances. Medical disputes often occur in the Emergency Department in China. Meanwhile, emergency nurses need to care for critically and seriously ill patients for a long time. In the process, their mind is highly stressed, their body is fatigued, and their sleep quality may be affected [59].

Nursing personnel with high night shift frequency per month may suffer from sleep disturbances more easily, which was consistent with the finding of other researchers $[42,60,61]$. Clinical nurses frequently take turns in working night shifts, which disturbs their body clock and results in irregular sleep patterns $[62,63]$. With the accelerating development of China's economy, more and more medical services are needed, especially in general hospitals; and nurses in general hospitals are relatively in shortage, such that the monthly night shift frequency of nurses increases. However, whether the additional workload could affect sleep disturbances in nurses would remain unclear as this study did not study the workload in night shifts. Nursing workload in night shifts may be heavy. Most often, nurses during night shifts work independently and lack group support. As such, nurses are more intense in night shifts than in day shifts. Their mind and body are in the stress state. Thus, their cerebral cortex malfunctions and their biological rhythm are disturbed, which may lead to sleep disturbances in nurses.

Our study also revealed that the sleep quality of temporary nurses was more easily affected than that of permanent nurses. Temporary employees experience more job insecurity than permanent ones $[64,65]$. Job insecurity has been identified as an important occupational stress factor [66], which contribute negatively to the psychological and physical health and well-being of employees [67-69]. Temporary nurses, who were more likely to be actually dismissed from work, were more likely to be stressed and work harder, in order to keep their job. Hence, this may lead to sleep disturbances. 


\section{A certain correlation between occupational stress and sleep disturbances}

Healthcare professionals, especially nurses, are highly stressed [70-72]. Job strain, a key component of work stress, is a measure of the balance between the psychological demand of a job and the amount of control or decision-making power it affords [18]. In our study, high psychological demand, low job control, and low workplace social support were associated with the development of sleep disturbances, which was similar to another study [73]. We found that scores for psychological demand and skill discretion correlated positively with sleep disturbances, while scores for decision-making authority correlated negatively with sleep disturbances. Working in the hospital is highly stressful, because workers need to deal with unpredictable medical conditions, have excessive workloads and working hours, are exposed to high levels of stress, and are frequently emotionally exhausted [25]. Meanwhile, nurses still need to continuously learn new knowledge, in order to improve their ability, meet job requirements and ensure promotion.

In the present study, clinical nurses sensed a lack of social support from supervisors and peers. In another study [74], work relationships have been proven to be a direct source of stress. Seeking support from coworkers or supervisors may actually represent a health-protecting behavior that could help diffuse the impact of stressors in the workplace [47]. Therefore, measures such as conflict resolution and peer support groups may be provided in tertiary hospitals in China, in order to decrease occupational stress, reduce the development of sleep disturbances and promote health.

\section{Limitations}

The limitations of this study include the use of crosssectional data and self-report measures. Although there are theoretically sound reasons to assume that the factors mentioned above could affect the sleep quality of nurses, no solid conclusion regarding causal relationships can be made from the data derived from this cross-sectional study. Whether the findings are applicable to all clinical nurses in Mainland China, this could not be assessed by only including one hospital nurse level in the study. The long-term sick leave nurses who did not participate in our study may be affected by sleep disturbances. The study included only QoL measurement and no specific depression or anxiety or other mental health (such as psychiatric disorders or medications) measures, which limited analyzing the relationship of mental health with sleep disturbances. Another limitation is that our study ignored the quantitative interaction between psychological, QoL, occupational and personal factors. Further research needs to consider the relative relationships of intermediate factors to establish sleep disturbances models for clinical nurses.

\section{Conclusions}

This study shows that the overall occurrence rate of sleep disturbances among clinical nurses in general hospitals in Mainland China is high. The risk factors for sleep disturbances in nurses were female gender, ICU and Emergency Department, many years of service, high night shift frequency, professional status: primary and intermediate, employment status: temporary, poor QoL: poor mental health, low perceived health, high occupational stress (high psychological demand, low job control and low workplace social support). Occupational stress plays an important role in the development of sleep disturbances in Chinese clinical nurses. In addition, sleep disturbances among clinical nurses have been a major psychological health problem in China, which needs to be solved urgently.

\section{Abbreviations \\ JCQ: Job Content Questionnaire; MCS: The Mental Component Summary; OR: Odds ratio; PCS: The Physical Component Summary; PSQI: Pittsburgh Sleep Quality Index; QoL: Quality of life; SF-12: The 12-item Short Form Health Survey}

\section{Acknowledgements}

We are grateful to all the nurses who participated in the study.

Funding

None.

Availability of data and materials

Data will not be shared because study participants did not give their approval in the informed consent.

\section{Authors' contributions}

HD and QZ designed the study and analyzed the data. ZS, FS and YX did the data collection and quality control. QZ wrote the manuscript and all of the authors prepared for the manuscript. All authors read and approved the final manuscript.

\section{Ethics approval and consent to participate}

The study was approved by the Ethics Committee of Shouguang People's Hospital. All participants in the study were voluntary and provided written informed consent before participating in this survey.

Consent for publication

Not applicable.

\section{Competing interests}

The authors declare that they have no competing interests.

\section{Publisher's Note}

Springer Nature remains neutral with regard to jurisdictional claims in published maps and institutional affiliations.

Received: 9 February 2017 Accepted: 27 June 2017

Published online: 03 July 2017

References

1. Ford DE, Kamerow DB. Epidemiologic study of sleep disturbances and psychiatric disorders. An opportunity for prevention? JAMA. 1989;262(11): 1479-84.

2. Mellinger GD, Balter MB, Uhlenhuth EH. Insomnia and its treatment. Prevalence and correlates. Arch Gen Psychiatry. 1985;42(3):225-32.

3. Ohayon MM, Smirne S. Prevalence and consequences of insomnia disorders in the general population of Italy. Sleep Med. 2002;3(2):115-20. 
4. Ohayon MM, Paiva T. Global sleep dissatisfaction for the assessment of insomnia severity in the general population of Portugal. Sleep Med. 2005; 6(5):435-41.

5. Mieda M, Sakurai T. Orexin (hypocretin) receptor agonists and antagonists for treatment of sleep disorders. Rationale for development and current status. CNS Drugs. 2013;27(2):83-90.

6. Rosado IV, Russo GH, Maia EM. Generating health elicits illness? The contradictions of work performed in emergency care units of public hospitals. Cien Saude Colet. 2015;20(10):3021-32

7. Kuppermann M, Lubeck DP, Mazonson PD, Patrick DL, Stewart AL, Buesching DP, Fifer SK. Sleep problems and their correlates in a working population. J Gen Intern Med. 1995;10(1):25-32.

8. Kling RN, McLeod CB, Koehoorn M. Sleep problems and workplace injuries in Canada. Sleep. 2010;33(5):611-8.

9. Shahly V, Berglund PA, Coulouvrat C, Fitzgerald T, Hajak G, Roth T, Shillington AC, Stephenson JJ, Walsh JK, Kessler RC. The associations of insomnia with costly workplace accidents and errors: results from the America insomnia survey. Arch Gen Psychiatry. 2012;69(10):1054-63.

10. Kessler RC, Berglund PA, Coulouvrat C, Hajak G, Roth T, Shahly V, Shillington AC, Stephenson JJ, Walsh JK. Insomnia and the performance of US workers: results from the America insomnia survey. Sleep. 2011:34(9):1161-71.

11. Nadaoka T, Kanda H, Oiji A, Morioka Y, Kashiwakura M, Totsuka S. Headache and stress in a group of nurses and government administrators in Japan. Headache. 1997;37(6):386-91.

12. Lin KC, Huang CC, Wu CC. Association between stress at work and primary headache among nursing staff in Taiwan. Headache. 2007;47(4):576-84.

13. Costa G. Shift work and occupational medicine: an overview. Occup Med (Lond). 2003;53(2):83-8.

14. Pallesen S, Bjorvatn B, Mageroy N, Saksvik IB, Waage S, Moen BE. Measures to counteract the negative effects of night work. Scand J Work Environ Health. 2010;36(2):109-20.

15. Vogel M, Braungardt T, Meyer W, Schneider W. The effects of shift work on physical and mental health. J Neural Transm (Vienna). 2012;119(10): 1121-32.

16. Bobbio A, Bellan M, Manganelli AM. Empowering leadership, perceived organizational support, trust, and job burnout for nurses: a study in an Italian general hospital. Health Care Manag Rev. 2012;37(1):77-87.

17. Feleke SA, Mulatu MA, Yesmaw YS. Medication administration error: magnitude and associated factors among nurses in Ethiopia. BMC Nurs. 2015;14:53.

18. Wilkins K, Beaudet MP. Work stress and health. Health Rep. 1998;10(3):47-62. (ENG); 49-66 (FRE).

19. Ming EE, Adler GK, Kessler RC, Fogg LF, Matthews KA, Herd JA, Rose RM. Cardiovascular reactivity to work stress predicts subsequent onset of hypertension: the air traffic controller health change study. Psychosom Med. 2004;66(4):459-65.

20. Akerstedt $T$, Knutsson A, Westerholm P, Theorell T, Alfredsson L, Kecklund G. Sleep disturbances, work stress and work hours: a cross-sectional study. J Psychosom Res. 2002;53(3):741-8.

21. Rusli BN, Edimansyah BA, Naing L. Working conditions, self-perceived stress, anxiety, depression and quality of life: a structural equation modelling approach. BMC Public Health. 2008;8:48.

22. Choenarom C, Williams RA, Hagerty BM. The role of sense of belonging and social support on stress and depression in individuals with depression. Arch Psychiatr Nurs. 2005:19(1):18-29.

23. Li J, Yang W, Cheng Y, Siegrist J, Cho Sl. Effort-reward imbalance at work and job dissatisfaction in Chinese healthcare workers: a validation study. Int Arch Occup Environ Health. 2005;78(3):198-204.

24. Gao YQ, Pan BC, Sun W, Wu H, Wang JN, Wang L. Depressive symptoms among Chinese nurses: prevalence and the associated factors. J Adv Nurs. 2012;68(5):1166-75.

25. Wilkins K. Work stress among health care providers. Health Rep. 2007;18(4): 33-6.

26. Patrick PK. Burnout: job hazard for health workers. Hospitals. 1979; 53(22):87-8. 90

27. Ndejjo R, Musinguzi G, Yu X, Buregyeya E, Musoke D, Wang JS, Halage AA, Whalen C, Bazeyo W, Williams P, et al. Occupational health hazards among healthcare workers in Kampala, Uganda. J Environ Public Health. 2015;2015: 913741

28. Tsai PS, Wang SY, Wang MY, Su CT, Yang TT, Huang CJ, Fang SC. Psychometric evaluation of the Chinese version of the Pittsburgh sleep quality index (CPSQI) in primary insomnia and control subjects. Qual Life Res. 2005;14(8):1943-52.

29. Wong WS, Fielding R. The co-morbidity of chronic pain, insomnia, and fatigue in the general adult population of Hong Kong: prevalence and associated factors. J Psychosom Res. 2012;73(1):28-34.

30. Buysse DJ, Reynolds CF 3rd, Monk TH, Berman SR, Kupfer DJ. The Pittsburgh sleep quality index: a new instrument for psychiatric practice and research. Psychiatry Res. 1989;28(2):193-213.

31. Buysse DJ, Reynolds CF 3rd, Monk TH, Hoch CC, Yeager AL, Kupfer DJ. Quantification of subjective sleep quality in healthy elderly men and women using the Pittsburgh sleep quality index (PSQI). Sleep. 1991;14(4): $331-8$.

32. Ware J Jr, Kosinski M, Keller SD. A 12-item Short-form health survey: construction of scales and preliminary tests of reliability and validity. Med Care. 1996:34(3):220-33.

33. Jenkinson C, Layte $R$, Jenkinson D, Lawrence $K$, Petersen S, Paice C, Stradling J. A shorter form health survey: can the SF-12 replicate results from the SF-36 in longitudinal studies? J Public Health Med. 1997;19(2): 179-86.

34. Gandek B, Ware JE, Aaronson NK, Apolone G, Bjorner JB, Brazier JE, Bullinger $M$, Kaasa $S$, Leplege A, Prieto $L$, et al. Cross-validation of item selection and scoring for the SF-12 health survey in nine countries: results from the IQOLA project. International quality of life assessment. J Clin Epidemiol. 1998;51(11):1171-8.

35. Lam CL, Tse EY, Gandek B. Is the standard SF-12 health survey valid and equivalent for a Chinese population? Qual Life Res. 2005;14(2):539-47.

36. Liang Y, Lu W, Wu W. Are social security policies for Chinese landless farmers really effective on health in the process of Chinese rapid urbanization? A study on the effect of social security policies for Chinese landless farmers on their health-related quality of life. Int J Equity Health. 2014;13:5

37. Yang WJ, Li J. Measurement of psychosocial factors in work environment: application of two models of occupational stress. Zhonghua Lao Dong Wei Sheng Zhi Ye Bing Za Zhi. 2004:22(6):422-6.

38. Li J, Yang W, Liu P, Xu Z, Cho Sl. Psychometric evaluation of the Chinese (mainland) version of job Content questionnaire: a study in university hospitals. Ind Health. 2004;42(2):260-7.

39. Wang $L$, Chen CK, Hsu SC, Lee SY, Wang CS, Yeh WY. Active job, healthy job? Occupational stress and depression among hospital physicians in Taiwan. Ind Health. 2011:49(2):173-84.

40. Karasek RA Jr. Job demands, job decison latitude, and mental strain: implications for job redesign. Adm Sci Q. 1979;242:285-308.

41. Karasek R, Brisson C, Kawakami N, Houtman I, Bongers P, Amick B. The job Content questionnaire (JCQ): an instrument for internationally comparative assessments of psychosocial job characteristics. J Occup Health Psychol. 1998;3(4):322-55.

42. Wang L, Qin P, Zhao Y, Duan S, Zhang Q, Liu Y, Hu Y, Sun J. Prevalence and risk factors of poor sleep quality among Inner Mongolia medical university students: a cross-sectional survey. Psychiatry Res. 2016;244:243-8.

43. Sadeghniiat-Haghighi K, Yazdi Z, Kazemifar AM. Sleep quality in long haul truck drivers: a study on Iranian national data. Chin J Traumatol. 2016:19(4): 225-8.

44. Li RH, Wing YK, Ho SC, Fong SY. Gender differences in insomnia-a study in the Hong Kong Chinese population. J Psychosom Res. 2002; 53(1):601-9.

45. Cho HS, Kim YW, Park HW, Lee KH, Jeong BG, Kang YS, Park KS. The relationship between depressive symptoms among female workers and job stress and sleep quality. Ann Occup Environ Med. 2013;25(1):12.

46. Ghalichi L, Pournik O, Ghaffari M, Vingard E. Sleep quality among health care workers. Arch Iran Med. 2013:16(2):100-3.

47. Tsai YC, Liu CH. Factors and symptoms associated with work stress and health-promoting lifestyles among hospital staff: a pilot study in Taiwan. BMC Health Serv Res. 2012;12:199.

48. Zhang B, Wing YK. Sex differences in insomnia: a meta-analysis. Sleep. 2006; 29(1):85-93

49. Lajoie P, Aronson KJ, Day A, Tranmer J. A cross-sectional study of shift work sleep quality and cardiometabolic risk in female hospital employees. BMJ Open. 2015:5(3):e007327.

50. Voderholzer U, Al-Shajlawi A, Weske G, Feige B, Riemann D. Are there gender differences in objective and subjective sleep measures? A study of insomniacs and healthy controls. Depress Anxiety. 2003;17(3):162-72. 
51. Schubert CR, Cruickshanks K, Dalton DS, Klein BE, Klein R, Nondahl DM. Prevalence of sleep problems and quality of life in an older population. Sleep. 2002;25(8):889-93.

52. Leger D, Scheuermaier K, Philip P, Paillard M, Guilleminault C. SF-36: evaluation of quality of life in severe and mild insomniacs compared with good sleepers. Psychosom Med. 2001;63(1):49-55.

53. Breslau N, Roth T, Rosenthal L, Andreski P. Sleep disturbance and psychiatric disorders: a longitudinal epidemiological study of young adults. Biol Psychiatry. 1996;39(6):411-8.

54. Roberts RE, Shema SJ, Kaplan GA, Strawbridge WJ. Sleep complaints and depression in an aging cohort: a prospective perspective. Am J Psychiatry. 2000;157(1):81-8.

55. Chang PP, Ford DE, Mead LA, Cooper-Patrick L, Klag MJ. Insomnia in young men and subsequent depression. The Johns Hopkins precursors study. Am J Epidemiol. 1997:146(2):105-14.

56. Wong WS, Fielding R. Prevalence of insomnia among Chinese adults in Hong Kong: a population-based study. J Sleep Res. 2011;20(1 Pt 1):117-26.

57. Benbir G, Demir AU, Aksu M, Ardic S, Firat H, Itil O, Ozgen F, Yilmaz H, Karadeniz D. Prevalence of insomnia and its clinical correlates in a general population in Turkey. Psychiatry Clin Neurosci. 2015;69(9):543-52.

58. Bjorvatn B, Dale S, Hogstad-Erikstein R, Fiske E, Pallesen S, Waage S. Selfreported sleep and health among Norwegian hospital nurses in intensive care units. Nurs Crit Care. 2012;17(4):180-8.

59. Trousselard M, Dutheil F, Naughton G, Cosserant S, Amadon S, Duale C, Schoeffler P. Stress among nurses working in emergency, anesthesiology and intensive care units depends on qualification: a job demand-control survey. Int Arch Occup Environ Health. 2016;89(2):221-9.

60. Zhang HS, Li Y, Mo HY, Qiu DX, Zhao J, Luo JL, Lin WQ, Wang JJ, Wang PX. A community-based cross-sectional study of sleep quality in middle-aged and older adults. Qual Life Res. 2017;26(4):923-33.

61. Yazdi Z, Sadeghniiat-Haghighi K, Loukzadeh Z, Elmizadeh K, Abbasi M. Prevalence of sleep disorders and their impacts on occupational performance: a comparison between shift workers and Nonshift workers. Sleep Disord. 2014;2014:870320

62. Korompeli A, Chara T, Chrysoula L, Sourtzi P. Sleep disturbance in nursing personnel working shifts. Nurs Forum. 2013;48(1):45-53.

63. Manenschijn L, van Kruysbergen RG, de Jong FH, Koper JW, van Rossum EF. Shift work at young age is associated with elevated long-term cortisol levels and body mass index. J Clin Endocrinol Metab. 2011;96(11):E1862-5.

64. Lee WW, Park JB, Min KB, Lee KJ, Kim MS. Association between work-related health problems and job insecurity in permanent and temporary employees. Ann Occup Environ Med. 2013;25(1):15.

65. Pirani E, Salvini S. Is temporary employment damaging to health? A longitudinal study on Italian workers. Soc Sci Med. 2015;124:121-31.

66. Burgard SA, Brand JE, House JS. Perceived job insecurity and worker health in the United States. Soc Sci Med. 2009;69(5):777-85.

67. Ferrie JE. Is job insecurity harmful to health? J R Soc Med. 2001;94(2):71-6.

68. Laszlo KD, Pikhart H, Kopp MS, Bobak M, Pajak A, Malyutina S, Salavecz G, Marmot M. Job insecurity and health: a study of 16 European countries. Soc Sci Med. 2010;70(6):867-74.

69. Muenster E, Rueger H, Ochsmann E, Letzel S, Toschke AM. Association between overweight, obesity and self-perceived job insecurity in German employees. BMC Public Health. 2011;11:162.

70. Buddeberg-Fischer B, Klaghofer R, Stamm M, Siegrist J, Buddeberg C. Work stress and reduced health in young physicians: prospective evidence from Swiss residents. Int Arch Occup Environ Health. 2008;82(1):31-8.

71. Sehlen S, Vordermark D, Schafer C, Herschbach P, Bayerl A, Pigorsch S, Rittweger J, Dormin C, Bolling T, Wypior HJ, et al. Job stress and job satisfaction of physicians, radiographers, nurses and physicists working in radiotherapy: a multicenter analysis by the DEGRO quality of life work group. Radiat Oncol. 2009:4:6.

72. Wheeler HH. A review of nurse occupational stress research: 1. Br J Nurs. 1997;6(11):642-5.

73. Nomura K, Nakao M, Sato M, Ishikawa H, Yano E. The association of the reporting of somatic symptoms with job stress and active coping among Japanese white-collar workers. J Occup Health. 2007:49(5):370-5.

74. Hope A, Kelleher CC, O'Connor M. Lifestyle practices and the health promoting environment of hospital nurses. J Adv Nurs. 1998;28(2):438-47.

\section{Submit your next manuscript to BioMed Central and we will help you at every step:}

- We accept pre-submission inquiries

- Our selector tool helps you to find the most relevant journal

- We provide round the clock customer support

- Convenient online submission

- Thorough peer review

- Inclusion in PubMed and all major indexing services

- Maximum visibility for your research

Submit your manuscript at www.biomedcentral.com/submit
Biomed Central 